\title{
Case Report: Caseous Calcification of the Mitral Annulus in an 88-Year-Old Woman
}

\author{
Giuseppe Fede, Giuseppe Abate, Paola Belluardo, Carmelo Di Tommasi, Maria Luisa Guarrella, \\ Nicoletta Guccione, Guglielmo Piccione, Salvatore Solarino, Giuseppe Sulsenti, Giovanni Tasca, \\ Sabina Ficili
}

Department of Cardiovascular Disease, Maggiore Hospital, Modica, Italy

Email: g_fede@tiscali.it

How to cite this paper: Fede, G., Abate, G., Belluardo, P., Di Tommasi, C., Guarrella, M.L., Guccione, N., Piccione, G., Solarino, S., Sulsenti, G., Tasca, G. and Ficili, S. (2020) Case Report: Caseous Calcification of the Mitral Annulus in an 88-Year-Old Woman. Open Journal of Internal Medicine, 10, 337-341.

https://doi.org/10.4236/ojim.2020.104035

Received: September 15, 2020

Accepted: October 27, 2020

Published: October 30, 2020

Copyright $\odot 2020$ by author(s) and Scientific Research Publishing Inc. This work is licensed under the Creative Commons Attribution International License (CC BY 4.0).

http://creativecommons.org/licenses/by/4.0/

\begin{abstract}
The caseous calcification of the mitral annulus (CCMA) is a rare variant of the mitral annulus calcification (MAC), with prevalence of $0.067 \%$ in general population. It is usually an asymptomatic condition but rarely it can cause severe mitral valve dysfunction, embolization, and conduction abnormalities. Transthoracic echocardiography (TTE) is a useful diagnostic tool. However, it can be necessary a multi-modality imaging approach for a differential diagnosis among other intra-cardiac masses. We are presenting a case of CCMA in an 88-year-old woman admitted to our department for acute decompensation of chronic heart failure. TTE has shown pathognomonic findings of CCMA. Tridimensional trans-esophageal echocardiography (3D TEE) gave a better characterization of the CCMA, avoiding further diagnostic procedures.
\end{abstract}

\section{Keywords}

Mitral Valve, Caseous Calcification, Tridimensional Echocardiography

\section{Introduction}

The mitral annular calcification (MAC) is a relatively common degenerative condition of the mitral valve affecting the elderly with an estimated prevalence of $8.5 \%$ in general population [1]. Caseous calcification of the mitral annulus (CCMA) is a rare variant of MAC, with a prevalence of $0.067 \%$ in general population, and $0.6 \%$ of patients with MAC [2] [3]. CCMA generally affects elderly women and it is more frequent in patients with hypertension, chronic kidney disease, and dyslipidemia [4] [5] [6] [7]. CCMA is usually an asymptomatic 
condition, associated with mild to moderate mitral regurgitation. However, it can cause severe mitral valve dysfunction and it could be necessary a surgical treatment. TTE, which is the initial imaging test, shows a typical intra-cardiac mass with a central echo-lucent area, calcified edges, without acoustic shadowing [8]. Sometimes, it can be necessary a multi-modality imaging approach, with computed tomography (CT) scan or cardiac magnetic resonance (MR) in order to make a differential diagnosis among other intra-cardiac masses [9].

We report a case of CCMA in an 88 years old woman, admitted to our department for acute decompensation of chronic heart failure.

\section{Case Presentation}

An 88-year-old woman was admitted to our department for acute decompensation of chronic heart failure. Her medical history included a chronic renal disease, arterial hypertention and a chronic coronary artery disease (previous percutaneous coronary interventions in 2002 and coronary artery bypass grafting in 2004). Physical examination revealed fine bilateral basal crackles, a pan-systolic murmur of grade $3 / 6$ in the mitral area, a mild pitting edema of the ankles. Laboratory tests were normal apart from creatinine $3 \mathrm{mg} / \mathrm{dl}$ (n.v. $<1.2 \mathrm{mg} / \mathrm{dl}$ ) and RCP $13 \mathrm{mg} / \mathrm{dl}$ (n.v. < $5 \mathrm{mg} / \mathrm{dl}$ ). A trans-thoracic echocardiography (TTE) showed a large an echodense mass $(43 \times 19 \mathrm{~mm})$ involving the posterior mitral annulus, with a central echo-lucent area, without acoustic shadowing (Figure 1). Doppler color flow mapping revealed a moderate mitral regurgitation, without obstruction to the diastolic trans-mitral flow. Other echocardiographic findings were left ventricle with normal size and normal wall motion, dilated left atrium (antero-posterior diameters of $46 \mathrm{~mm}$ ), normal right atrium and right ventricles.

A tridimensional trans-esophageal echocardiography (3D TEE) was performed to evaluate the mass better, after obtaining from patient a written informed consent to perform the examination and to use her clinical information for scientific purposes. 3D TEE confirmed the previous findings and it allowed a better characterization of the mass: it involved the whole posterior annulus, causing a reduced motion of the posterior mitral leaflet (PML), whereas the anterior mitral leaflet (AML) was normal in motion and morphology (Figure 2 and Figure 3).
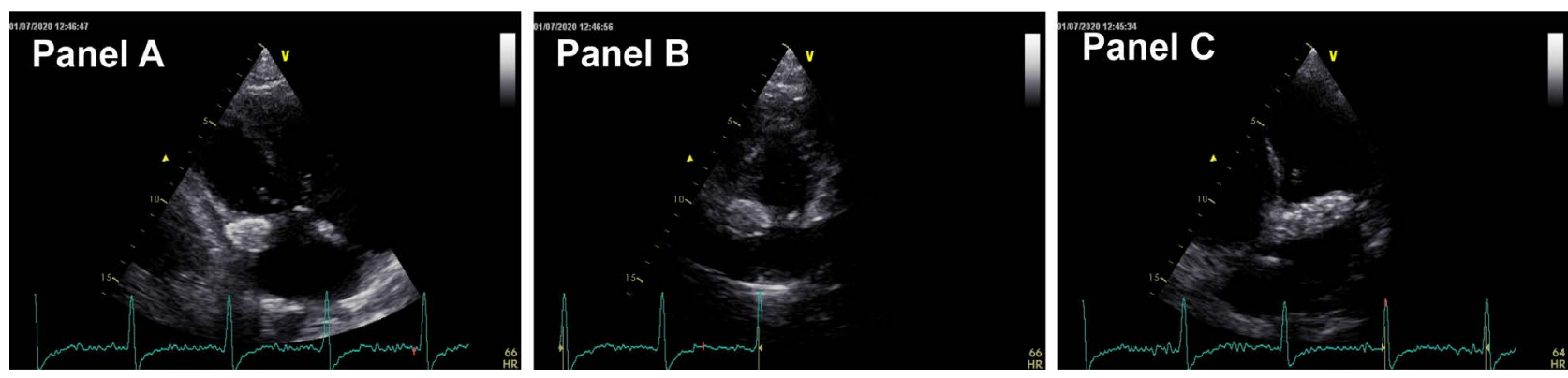

Figure 1. Transthoracic two-dimensional visualization of the mass: (A) Apical long axis view; (B) Parasternal short axis view; (C) Apical four chamber view. 

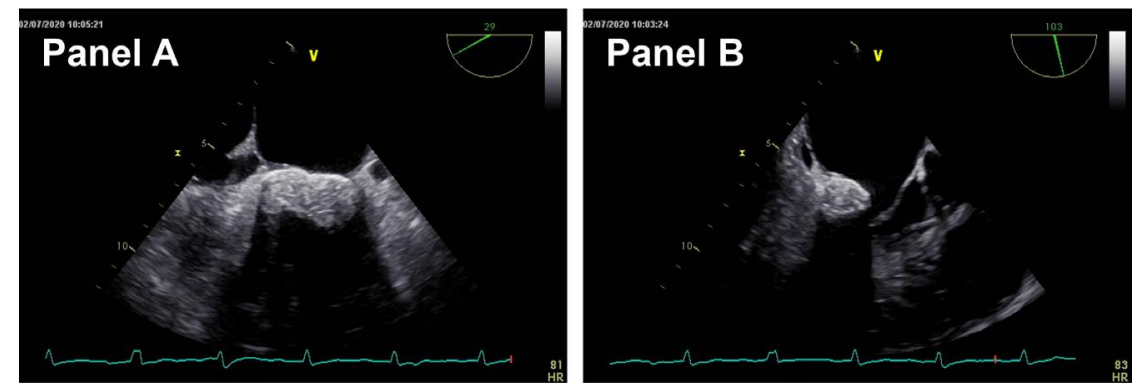

Figure 2. Trans-esophageal two-dimensional visualization of the mass involving the whole posterior mitral valve annulus (A), whereas anterior mitral valve annulus is spared (B).
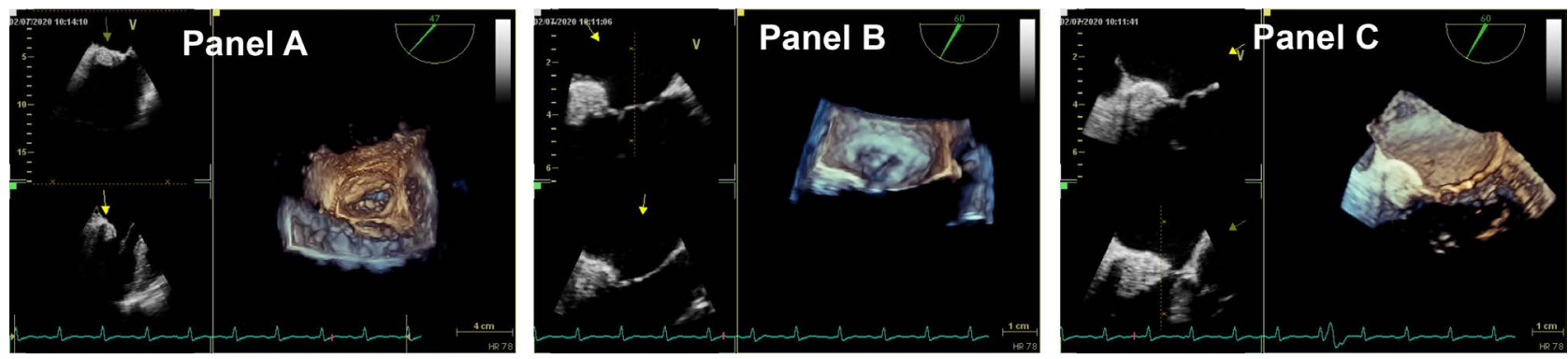

Figure 3. Tridimensional-transesophageal visualization of the mass (A, B and C).

A presumptive diagnosis of CCMA was made based on the echocardiographic findings. We did not perform other diagnostic procedures, like CT scan or cardiac MR, because the patient had severe renal failure, and a contrast agent could have further damage renal function. We discharged the patient with indication of regular clinical and echocardiographic follow-up.

\section{Discussion}

CCMA is a chronic degenerative process of the mitral valve, usually located in the posterior fibrous annulus which represents a variant of the more frequent mitral annular calcification [1]. It is a mass formed by a "toothpaste-like" core, composed of fatty acid, cholesterol and calcium, surrounded by a calcified envelope. It's a rare condition, with a prevalence of $0.067 \%$ in general population, and $0.6 \%$ of patients with MAC [2] [3]. The precise etiopathogenesis of CCMA is unknown; however it can be associated with an altered calcium phosphate metabolism and atherosclerosis. In fact, it is more frequent in patients with multiple cardiovascular risks, with hypertension, chronic kidney disease, dyslipidemia [4] [5] [6] [7].

Usually CCMA is discovered occasionally during a routine TTE. It appears as an intra-cardiac mass with a central echo-lucent area, calcified edges, without acoustic shadowing [9]. Often it is located in the posterior mitral annulus and it is associated with middle to moderate mitral regurgitation. Rarely it can cause mitral stenosis, embolization or conduction abnormalities. TEE can give more detailed information regarding echogenic characterization, Doppler signal, especially in patients with pour acoustic windows at the TTE. Sometimes it can be 
necessary a multi-modality imaging approach [8] to make a differential diagnosis among other intra-cardiac masses. CT and cardiac MR are important tools for a better characterization of the lesion [10], being the latter superior with the best tissue characterization [11].

Common differential diagnoses include benign and malignant primary cardiac tumors, secondary cardiac tumors, myocardial abscess and vegetations, thrombus.

The prognosis is usually benign and the treatment conservative. The surgical treatment is reserved to complicated cases, as severe mitral valve dysfunction or when the diagnosis remains uncertain [12] [13]. Embolic phenomena could occur and could request anticoagulation treatment [14]. Conduction abnormalities are uncommon, and PM implantation could be necessary [15].

In our case the TTE findings were pathognomonic of CCMA and 3D TEE allowed a better characterization of the mass. We decided not to go forward with other imaging techniques, due to the severe kidney disease of the patients, and we opted for a close follow-up.

\section{Conclusion}

CCMA is a rare chronic degenerative condition of the mitral valve. It is usually asymptomatic and it is discovered occasionally during routine TTE. However differential diagnosis with other intra-cardiac masses can be difficult. A 3D TEE is useful to well characterized CCMA, avoiding other complex diagnostic tests.

\section{Conflicts of Interest}

The authors declare no conflicts of interest regarding the publication of this paper.

\section{References}

[1] Pomerance, A. (1970) Pathological and Clinical Study of Calcification of the Mitral Valve Ring. Journal of Clinical Pathology, 23, 354-361. https://doi.org/10.1136/jcp.23.4.354

[2] Deluca, G., Correale, M., Ieva, R., Del Salvatore, B., Gramenzi, S. and Di Biase, M. (2008) The Incidence and Clinical Course of Caseous Calcification of the Mitral Annulus: A Prospective Echocardiographic Study. Journal of the American Society of Echocardiography, 21, 828-833. https://doi.org/10.1016/j.echo.2007.12.004

[3] Harpaz, D., Auerbach, I., Vered, Z., Motro, M., Tobar, A. and Rosenblatt, S. (2001) Caseous Calcification of the Mitral Annulus: A Neglected, Unrecognized Diagnosis. Journal of the American Society of Echocardiography, 14, 825-831. https://doi.org/10.1067/mje.2001.111877

[4] Adler, Y., Fink, N., Spector, D., Wiser, I. and Sagie, A. (2001) Mitral Annulus Calcification: A Window to Diffuse Atherosclerosis of the Vascular System. Atherosclerosis, 155, 1-8. https://doi.org/10.1016/S0021-9150(00)00737-1

[5] Antonini-Canterin, F., Capanna, M., Manfroni, A., Brieda, M., Grandis, U., et al. (2001) Association between Mitral Annular Calcium and Carotid Artery Stenosis and Role of Age and Gender. The American Journal of Cardiology, 88, 581-583. 
https://doi.org/10.1016/S0002-9149(01)01747-7

[6] Akram, M. and Hasanin, A.M. (2012) Caseous Mitral Annular Calcification: Is It a Benign Condition? Journal of the Saudi Heart Association, 24, 205-208. https://doi.org/10.1016/j.jsha.2012.02.003

[7] Abramowitz, Y., Jilaihawi, H., Chakravarty, T., Mack, M.J. and Makkar, R.R. (2015) Mitral Annulus Calcification. Journal of the American College of Cardiology, 66, 1934-1941. https://doi.org/10.1016/j.jacc.2015.08.872

[8] Pomeroy, W.L., Markelz, B., Steel, K. and Slim, A.M. (2013) Mitral Annular Caseous Calcification: A Rare Variant of a Common Echocardiographic Finding Discovered with Advanced Imaging Techniques. Case Reports in Medicine, 2013, Article ID: 972684. https://doi.org/10.1155/2013/972684

[9] Kurnicka, K., Samul, J., Piotrowska-Kownacka, D., Wisniewska, M., Lipinska, A. and Pruszczyk, P. (2017) Multimodal Diagnosis of Caseous Calcification of the Mitral Annulus in a Patient with Suspected Left Ventricular Tumor. Polish Archives of Internal Medicine, 127, 281-282. https://doi.org/10.20452/pamw.4004

[10] Vanovermeire, O.M., Duerinckx, A.J., Duncan, D.A. and Russell, W.G. (2006) Caseous Calcification of the Mitral Annulus Imaged with 64-Slice Multidetector CT and Magnetic Resonance Imaging. International Journal of Cardiovascular Imaging, 22, 553-559. https://doi.org/10.1007/s10554-005-9069-0

[11] Hoffmann, U., Globits, S., Schima, W., et al. (2003) Usefulness of Magnetic Resonance Imaging of Cardiac and Paracardiac Masses. The American Journal of Cardiology, 92, 890-895. https://doi.org/10.1016/S0002-9149(03)00911-1

[12] Teja, K., Gibson, R.S. and Nolan, S.P. (1987) Atrial Extension of Mitral Annularcalcification Mimicking Intracardiac Tumor. Clinical Cardiology, 10, 546-548. https://doi.org/10.1002/clc.4960100918

[13] Borowski, A., Korb, H., Voth, E. and de Vivie, E.R. (1988) Asymptomatic Myocardialabscess. The Thoracic and Cardiovascular Surgeon, 36, 338-340. https://doi.org/10.1055/s-2007-1022976

[14] Hamdi, I., Chourabi, C., Arous, Y., et al. (2018) Multimodality Imaging Assessment of a Caseous Calcification of the Mitral Valve Annulus. Journal of the Saudi Heart Association, 30, 55-58. https://doi.org/10.1016/j.jsha.2017.04.007

[15] Fong, L.S., McLaughlin, A.J., Okiwelu, N.L., Nordstrand, I.A.J., Newman, M., Passage, J. and Joshi, P.V. (2017) Surgical Management of Caseous Calcification of the Mitral Annulus. The Annals of Thoracic Surgery, 104, e291-e293.

https://doi.org/10.1016/j.athoracsur.2017.04.039

\section{Abbreviations}

MAC: Mitral annular calcification, CCMA: Caseous calcification of the mitral annulus, TTE: Trans-thoracic echocardiography, NV: Normal values, 3D TTE: Tridimensional transoesophageal echocardiography, PML: Posterior mitral leaflet, AML: Anterior mitral leaflet, CT: Computed tomography, MR: Magnetic resonance. 